\title{
ANALISIS KESIAPAN IMPLEMENTASI E-LEARNING MENGGUNAKAN E-LEARNING READINESS MODEL
}

\author{
Ronny Faslah' ${ }^{1)}$, Harry Budi Santoso ${ }^{2)}$ \\ ${ }^{1}$ Magister Teknik Informatika Universitas AMIKOM Yogyakarta \\ email: ronnyfaslah@gmail.com \\ ${ }^{2}$ Fakultas Ilmu Komputer Universitas Indonesia \\ email: harrybs@cs.ui.ac.id
}

\begin{abstract}
Abstrak
Keberhasilan penerapan e-Learning pada suatu perguruan tinggi dipengaruhi oleh banyak faktor. Salah satu faktor tersebut adalah kesiapan perguruan tinggi untuk menggunakan e-Learning dalam proses belajar mengajar. E-Learning Readiness (ELR) merupakan instrumen yang dikembangkan oleh Aydin dan Tasci untuk mengukur tingkat kesiapan penerapan e-Learning di negara berkembang yang dikelompokkan dalam empat faktor yaitu teknologi, inovasi, manusia, dan pengembangan diri. Penelitian ini bertujuan untuk mengetahui tingkat kesiapan implementasi e-Learning dalam proses belajar mengajar di Politeknik Hasnur. Hasil penelitian menujukkan Politeknik Hasnur termasuk dalam kategori siap dalam menerapkan e-learning tetapi membutuhkan peningkatan pada beberapa faktor.
\end{abstract}

Kata Kunci: e-Learning, Readiness.

\begin{abstract}
The successful implementation of e-Learning in a college is influenced by many factors. One of these factors is the readiness of universities to use e-Learning in teaching and learning process. E-Learning Readiness (ELR) is an instrument developed by Aydin and Tasci to measure the level of readiness of eLearning implementation in developing countries grouped into four factors: technology, innovation human, and self-development. This study aims to determine the level of readiness of e-Learning implementation in teaching and learning process at Hasnur Polytechnic. The results showed that Hasnur Polytechnic is included in the ready category in applying e-learning but requires an improvement on several factors.
\end{abstract}

Keywords: e-Learning, Readiness.

\section{PENDAHULUAN}

Teknologi yang kini ada pada dunia pendidikan, yaitu salah satunya sistem pembelajaran e-Learning. Teknologi e-Learning hadir sebagai sarana penunjang pendidikan pada saat ini dimana e-Learning hadir membawa warna baru dalam perubahan sistem pendidikan. ELearning (electronic learning) adalah salah satu aspek penerapan TIK pada institusi pendidikan. $E$ Learning didefinisikan sebagai penyampaian konten pembelajaran atau pengalaman belajar secara elektronik mengunakan komputer dan media berbasis komputer (Stockley, 2003). Namun penyediaan infrastruktur teknologi dan pelatihan SDM sama sekali belum menjamin keberhasilan e-Learning, kultur organisasi dan faktor leadership memiliki pengaruh yang besar terhadap keberhasilan e-Learning. Beberapa peneliti lain juga mendefinisakan dengan arti yang hampir sama. Seperti Clark dan Mayer menyatakan "Kami mendefinisikan e-Learning sebagai instruksi yang disampaikan pada perangkat digital seperti komputer atau perangkat mobile yang ditujukan untuk menunjang pembelajaran" (Clark \& Mayer, 2011). Pernyataan hampir serupa disampaikan oleh Ong dkk. "Isi instruksional atau pengalaman belajar yang disampaikan atau diaktifkan dengan teknologi elektronik" (Ong, Lai, \& Wang, 2004). Argumen lain menyatakan bahwa dengan implementasi e-Learning diharapkan meningkatkan kualitas pendidikan. Agar bisa bersaing perguruan tinggi harus bisa beradaptasi dan mengadopsi e-Learning (Wannemacher, 2006). Ini Sama halnya dengan Gotthardt menyatakan bahwa penggunaan teknologi dalam pembelajaran bisa menciptakan lingkungan yang kompetitif, siswa dan guru menjadi lebih kreatif dan inovatif (Gotthardt, Siegert, Schlieck, Schneider, Kohnert, \& Gross, 2006). 
Yang selanjutnya harus ditekankan adalah kemauan untuk mengadopsi teknologi baru. Penerapan teknologi pendidikan merupakan isu yang kompleks; konsep dan konsep pedagogis instruktur seringkali tidak menggunakan TIK dalam setting pendidikan meskipun teknologi tidak menjadi masalah bagi mereka (Steel, 2009). Akibatnya, penerapan e-Learning di mana-mana dibatasi oleh tidak adanya pandangan menyeluruh tentang apa yang harus dilakukan agar efektif dan tahan terhadap perubahan di antara staf akademik (Blin \& Monro, 2008). Kreativitas pribadi dan kecemasan komputer merupakan tantangan lain yang mungkin penting bagi keberhasilan Learning Management System (LMS). Kreativitas pribadi dalam konteks teknologi informasi adalah sikap individu yang mencerminkan kecenderungan untuk bereksperimen dan mengadopsi teknologi informasi baru secara independen dari pengalaman komunikasi orang lain (Al-Busaidi \& Al-Shihi, 2012). Hal ini seringkali sulit bagi para akademisi karena berbagai alasan: kurangnya pengalaman, keterampilan, dan pola pikir teknologi (Watts, 2007).

Mengadopsi pendekatan baru terhadap pendidikan ini membutuhkan waktu investasi yang cukup lama. Meskipun salah satu tujuan utama TIK dalam pendidikan adalah mempercepat prosesnya, banyak ilmuwan menggarisbawahi bahwa pengelolaan kursus $e$ Learning secara terus menerus membuat pekerjaan instruktur sangat memakan waktu (Gillard, Bailey, \& Nolan, 2008). Isu penting lainnya adalah efektivitas sistem manajemen pembelajaran yang dapat dianalisis melalui beberapa parameter: sejauh mana LMS digunakan oleh pemangku kepentingan dan kepuasan mereka (Naveh, Tubin, \& Pliskin, 2012).

Beberapa penelitian terdahulu sudah dilakukan dalam rangka menilai adopsi sistem yang baru terkait penerimaan (acceptance), kesiapan (readiness) atau kepuasan (satisfaction) karena perkembangan TI di bidang rekayasa perangkat lunak tidak serta-merta berpengaruh secara positif terhadap adopsi perangkat lunak itu sendiri pada level konsumen (Standish, 2014). Riset-riset sebelumnya mengenai faktor-faktor yang mempengaruhi pengguna atas teknologi komputer menggunakan dua model sebagai dasar teori yaitu: Theory of Reasoned Action (TRA); dan Technology Acceptance Model (TAM).

TAM mengadaptasi model umum dari TRA, dengan menggunakan dua variavel yaitu: perceived ease of use (persepsi kemudahaan penggunaan) dan perceived usefulness (persepsi kegunaan). Salah satu misi dari penelitian sistem informasi adalah untuk dapat mempelajari desain, pengiriman, penggunaan dan dampak dari teknologi informasi yang efektif dalam organisasi dan masyarakat. Berkenaan dengan efektifitas sistem informasi yang sulit diukur secara langsung (Peffers, Tuunanen, Rothenberger, \& Chatterjee, 2007).

Berkenaan dengan efektifitas sistem informasi yang sulit diukur secara langsung, karakteristik individu menjadi salah satu pusat perhatian dalam menentukan faktor yang berpengaruh terhadap penerimaan seseorang terhadap sistem informasi/teknologi baru. Salah satunya adalah kesiapan individu dalam menggunakan teknologi secara umum. Salah satu model evaluasi $e$ Learning readiness untuk negara berkembang adalah model Aydin and Tasci (2005) yang mengembangkan model ELR dengan empat faktor yang mampu mengukur kesiapan $e$ Learning, antara lain faktor teknologi, faktor inovasi, faktor manusia dan faktor pengembangan diri (Aydin \& Tasci, 2005).

Chapnick (2000) memperingatkan bahwa harus berhati-hati dalam proses adopsi e-Learning untuk suatu organisasi. Mereka menagaskan bahwa adopsi e-Learning tanpa perencanaan yang cermat kemungkinan besar akan berakhir dengan cost overruns, produk pembelajaran yang tidak menarik, dan kegagalan. Oleh karena itu penelitian tentang tingkat kesiapan penerapan $e$ Learning perlu dilakukan sehingga hasil penelitian dapat menjadi bahan pertimbangan bagi instansi yang menerapkan e-Learning. Pertimbangan tersebut dimaksudkan agar pemanfaatan e-Learning dapat dirancang dengan cermat. Jika tidak dirancang dengan cermat, justru penggunaan e-Learning dapat merugikan instansi yang memanfaatkannya (Chapnick, 2000).

Politeknik Hasnur telah menerapkan pembelajaran menggunakan e-Learning. Tetapi dalam pelaksanaannya, masih banyak ditemui adanya kekurangan. Kendala-kendala yang dihadapi oleh Politeknik Hasnur merupakan kendala umum yang dialami oleh banyak perguruan tinggi di Indonesia, seperti infrastruktur, sumber daya manusia, dan konten pembelajaran. cakupan akses internet dan ketersediaan bandwidth yang masih terbatas merupakan kendala dari sisi infrastruktur. Dari sisi sumber daya manusia, belum siapnya tenaga pendidik, tenaga kependidikan dan mahasiswa dalam menerima perubahan metode pembelajaran. Sedangkan dari sisi konten 
pembelajaran, kendala yang dihadapi adalah kurangnya konten pembelajaran berbasis multimedia yang dimiliki oleh tenaga pendidik.

Penerapan e-Learning membutuhkan kesiapan baik infrastruktur maupun organisasi yang menaungi sistem e-Learning tersebut. Analisis yang dilakukan terhadap sistem e-Learning pada Politeknik Hasnur ini dilakukan agar dapat mengetahui tingkat kesiapan dari pihak institusi terhadap sistem tersebut. Dengan mengetahui tingkat kesiapannya, pihak penyedia sistem dapat menentukan kebijakan atau strategi apa yang akan ditentukan. Dengan alasan itulah, perlu dianalisis kesiapan dari institusi penyedia untuk melakukan pengembangan tahapan dalam e-Learning. Model yang digunakan adalah model E-Learning Readiness dari Aydin and Tasci (2005).

\section{TINJAUAN PUSTAKA}

Pada penelitian yang dilakukan oleh (Wuryanto \& Insani, 2013) yang berjudul "Tingkat Kesiapan (Readiness) Implementasi ELearning di Sekolah Menengah Atas Kota Yogyakarta" bertujuan untuk mengetahui tingkat kesiapan sekolah dan mengungkap faktor atau area mana yang masih lemah dan memerlukan perbaikan dan area mana yang sudah dianggap berhasil atau kuat dalam mendukung penerapan e-Learning dalam proses pembelajaran model yang digunakan adalah E-Learning Readiness oleh (Chapnick, 2000) dengan menggunakan delapan faktor readiness untuk mengukur ELR, yaitu psychological readiness, sociological readiness, environmental readiness, human resource readiness, financial readiness, technological skill (aptitude) readiness, equipment readiness, dan content readiness.

Hasil dari penelitian ini menunjukan bahwa instansi pengguna e-Learning cukup siap untuk menggunakan e-Learning hal ini dibuktikan dengan hasil penelitian menunjukkan bahwa $e$ Learning readiness SMA Kota Yogyakarta mempunyai skor 103,76. Skor ini menurut model Chapnick masuk dalam kategori cukup siap. Kekurangan dari penelitian ini adalah peneliti tidak memasukan faktor ketidaknyamanan pengguna dan ketidakamanan dalam penelitian sehingga ketika e-Learning di implementasikan faktor ini bisa jadi penghambat.

Pada penelitian (Pamukti, Hartanto, \& Winarno, 2017) yang berjudul "Model Analisis Kesiapan Individu dalam Penerapan Manajemen Pengetahuan di Instansi Pemerintah" menggunakan model Knowledge Manajemen
Readiness (KM Readiness) dan digabungkan dengan model Technology Readiness Index (TRI) sehingga faktor yang di analisis adalah empat faktor dari TRI yaitu optimisme, inovasi, ketidaknyamanan dan ketidakamanan digabungkan dengan tiga faktor dari $\mathrm{KM}$ Readiness yaitu budaya organisasi, struktur organisasi dan insfrastruktur teknologi informasi khususnya pada knowledge management sehingga faktor tentang pengembangan diri belum dianalisis pada penelitian ini.

Hasil dari penelitian ini, semua hipotesis yang diusulkan setelah melalui kajian sesuai dengan model penelitian yang diusulkan. Kemudian model penelitian diteliti menggunakan kuesioner yang sudah disesuaikan. Hasil dari kuesioner akan mengukur hubungan antar masing-masing variabel dalam penelitian ini. Model yang diusulkan merupakan penggabungan dari model konseptual KM Readiness dengan Technology Readiness Index. Variabel yang ada dalam penelitian ini disesuaikan dengan kondisi individu di lingkup instansi pemerintahan.

Pada penelitian (Astuti \& Nasution, 2014) yang berjudul "Technology Readiness and ECommerce Adoption among Entrepreneurs of SMEs in Bandung City, Indonesia" mengadopsi model TRI dari (Parasuraman, 2000) melakukan analisis data e-commerce di kota Bandung. Penelitian ini hanya menganalisis terhadap faktor yang ada pada TRI yaitu optimisme, inovasi, ketidaknyamanan dan ketidakamanan untuk faktor teknologi dan manusia tidak di analisis sehingga hasil penelitian tidak dapat dijadikan ukuran kesiapan teknologi.

Hasil dari penelitian ini adalah menunjukkan bahwa kesiapan teknologi dari entrepreneur masih moderat. Ada perbedaan yang signifikan dalam hal kesiapan teknologi jika dilihat dari latar belakang mereka (jenis kelamin, usia, pendidikan, dan pendapatan). Sehubungan dengan tingkat adopsi internet untuk media promosi masih rendah, hanya ada 36.3 persen yang mengadopsinya. Hal ini jelas menunjukkan perlunya untuk memberikan dukungan kepada UKM untuk mengadopsi teknologi khususnya untukpenggunaan e-commerce. Hasil penelitian memberikan implikasi tidak hanya untuk para manajer UKM tetapi juga untuk instansi pemerintah di negara-negara berkembang seperti Indonesia. Temuan ini juga memiliki implikasi bagi para peneliti dan praktisi dalam mengidentifikasi pendorong kesiapan teknologi (optimisme dan inovasi) dan hambatan (ketidaknyamanan dan ketidakamanan), yang 
berkontribusi secara efektif membantu meningkatkan penggunaan internet di UKM.

Pada penelitian (Fariani, 2013) mengadopsi model dari (Aydin \& Tasci, 2005) yaitu ELearning Readiness penelitian ini menganalisis enam faktor kesiapan dalam penerapan $e$ Learning antara lain human resource, kultur organisasi, teknologi, kebijakan, keadaan keuangan organisasi dan infrastruktur. Penelitian ini tidak melakukan modifikasi pada model ELR sehingga faktor tentang kenyamanan pengguna, inovasi dan faktor ketidakamanan sistem tidak dapat dianalisis.

Hasil dari penelitian ini menunjukkan perguruan tinggi $\mathrm{ABC}$ mempunyai indeks $e$ Learning Readiness sebesar 3.07 dari 3.40 yang diharapkan sebagai standar dari sebuah organisasi, yang berarti bahwa perguruan tinggi tersebut belum siap dalam melakukan implementasi e-Learning dan membutuhkan beberapa perbaikan. Beberapa rekomendasi diusulkan untuk perguruan tinggi $\mathrm{ABC}$ terkait dengan penelitian ini, yaitu pembuatan manajemen SOP, manajemen proyek, dan pembuatan IT Plan yang akan memberi arahan terhadap investasi TI, penyediaan infrastruktur dan optimalisasi struktur organisasi.

Penelitian (Angraini \& Suryadi, 2015) yang berjudul "Pengukuran Tingkat Kesiapan Penerapan E-Learning Menggunakan TRI (Technology Readiness Index), Studi Kasus: UIN Suska Riau" peneliti mengadopsi Technology Readiness Index untuk menganalisis faktor kesiapan implementasi e-Learning ada empat faktor yang digunakan yaitu inovasi, optimisme, ketidaknyamanan dan ketidakamanan. Penelitian ini tidak melakukan modifikasi pada model penelitian sehingga faktor yang diluar model TRI tidak dapat dianalisis.Hasil dari penelitian ini adalah dapat ditentukan nilai tingkat kesiapan penerapan e-Learning di fakutas Sains dan Teknologi adalah 3,36 yang artinya Not Ready, membutuhkan/memerlukan persiapan beberapa aspek untuk mencapai keberhasilan penerapan $e$ Learning.

Penelitian (Oketch, Njihia, \& Wausi, 2014) yang berjudul E-Learning Readiness Assessment Model In Kenyas' Higher Education Institutions: A Case Study Of University Of Nairobi bertujuan untuk menganalisis kesiapan e-Learning pada universitas Nairobi dengan mempertimbangkan 4 faktor antara lain Technological, Culture, Content dan Demographic Factor. Hasil yang didapatkan menunjukkan bahwa mayoritas sangat siap. Selain itu, hasil penelitian menunjukkan bahwa tidak ada hubungan yang signifikan antara umur, jenis kelamin, dan tingkat pendidikan tentang kesiapan belajar. Hasil penelitian menunjukkan bahwa kesiapan teknologi adalah yang paling banyak faktor penting diikuti oleh kesiapan budaya. Sebagian besar dosen merasa bahwa lebih banyak pelatihan cara membuat konten pembelajaran perlu dilakukan. Kesimpulannya, para dosen siap untuk e-Learning namun ICT infrastruktur tidak cukup memadai untuk mendukung penggunaan e-Learning.

\section{METODE PENELITIAN}

Penelitian ini merupakan penelitian deskriptif untuk menggambarkan fenomena-fenomena yang ada baik yang bersifat alamiah maupun rekayasa manusia. Penelitian ini menggunakan instrumen kuesioner yang dikembangkan oleh Aydin dan Tasci yang terdiri dari 37 item pertanyaan. Skala penilaian kuesioner menggunakan skala Likert $(1-5)$.

Untuk pengolahan data, dilakukan dengan cara mengelompokkan data hasil kuesioner sesuai dengan variabel penelitian, mencari nilai rata-rata pada setiap kelompok variabel penelitian, menentukan tingkat kesiapan untuk tiap kelompok variabel, menentukan tingkat kesiapan penerapan e-Learning pada level program studi dan menentukan tingkat kesiapan penerapan e-Learning pada level institusi.

Tingkat kesiapan digambarkan menggunakan skala penilaian seperti pada gambar 1 .

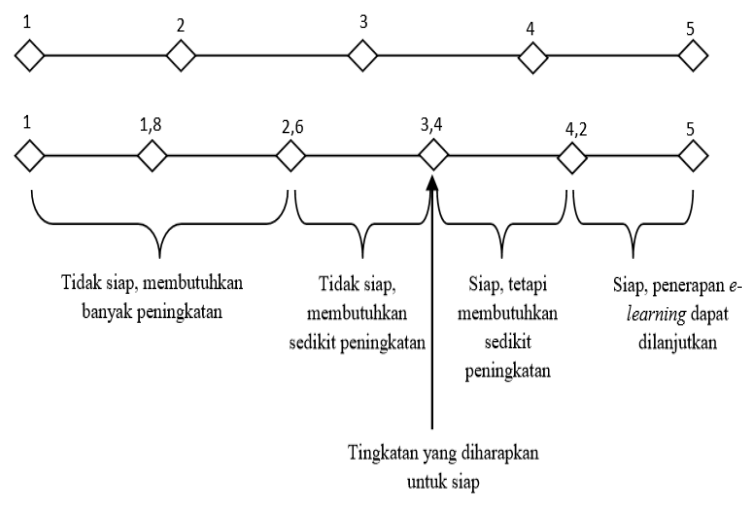

Gambar 1. Skala Penilaian Kesiapan E-Learning

Responden pada penelitian ini adalah dosendosen Politeknik Hasnur yang terdiri dari 9 dosen Program Studi Budidaya Tanaman Perkebunan (BTP), 9 dosen Program Studi Teknik Informatika (TI) dan 12 dosen Program Studi Teknik Otomotif (TO). 


\section{HASIL DAN PEMBAHASAN}

Dari hasil pengolahan data didapatkan hasil bahwa pada tingkat institusi Politeknik Hasnur memiliki indeks kesiapan penerapan e-Learning sebesar 3,41 yang diartikan Politeknik Hasnur termasuk dalam kategori siap tetapi membutuhkan sedikit peningkatan dalam menerapkan e-Learning dalam proses belajar mengajar.

Tabel 1. Indeks E-Learning Readiness

\begin{tabular}{|l|c|c|c|c|}
\hline \multirow{2}{*}{ Faktor } & \multicolumn{3}{|c|}{ Program Studi } & \multirow{2}{*}{ Institusi } \\
\cline { 2 - 4 } & BTP & TI & TO & \\
\hline Manusia & 3,75 & 3,47 & 3,47 & 3,56 \\
\hline $\begin{array}{l}\text { Pengembangan } \\
\text { Diri }\end{array}$ & 3,31 & 3,54 & 3,26 & 3,37 \\
\hline Teknologi & 3,26 & 3,32 & 3,16 & 3,25 \\
\hline Inovasi & 3,33 & 3,35 & 3,65 & 3,45 \\
\hline Rata-Rata & 3,41 & 3,42 & 3,39 & 3,41 \\
\hline
\end{tabular}

Sumber : Data diolah (2017)

Gambar 2 menunjukkan bahwa Politeknik Hasnur harus melakukan peningkatan pada faktor pengembangan diri dan faktor teknologi.

Hal-hal yang memerlukan peningkatan pada faktor pengembangan diri terkait dengan anggaran untuk keberlangsungan penerapan $e$ Learning, pengelolaan waktu serta kepercayaan diri baik dari sisi pengelola, dosen dan mahasiswa. Pada faktor teknologi yang memerlukan peningkatan adalah penyediaan infrastruktur teknologi informasi yang memiliki reliabilitas yang baik.

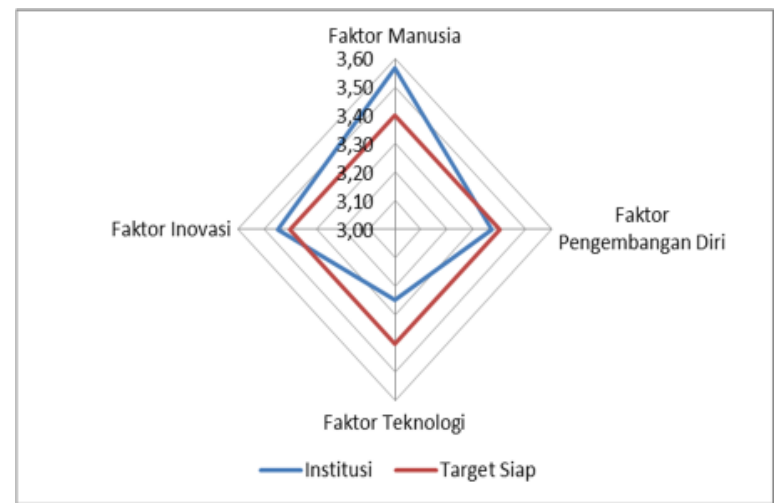

Gambar 2. Index E-Learning Readiness Level Institusi

Pada level program studi, hasil penelitian menunjukkan bahwa program studi BTP dan TI termasuk dalam kategori siap tetapi membutuhkan sedikit peningkatan dalam menerapkan e-Learning dalam proses belajar mengajar dengan nilai rata-rata masing-masing 3,41 dan 3,42. Sedangkan program studi TO termasuk dalam kategori tidak siap karena masih membutuhkan beberapa peningkatan.

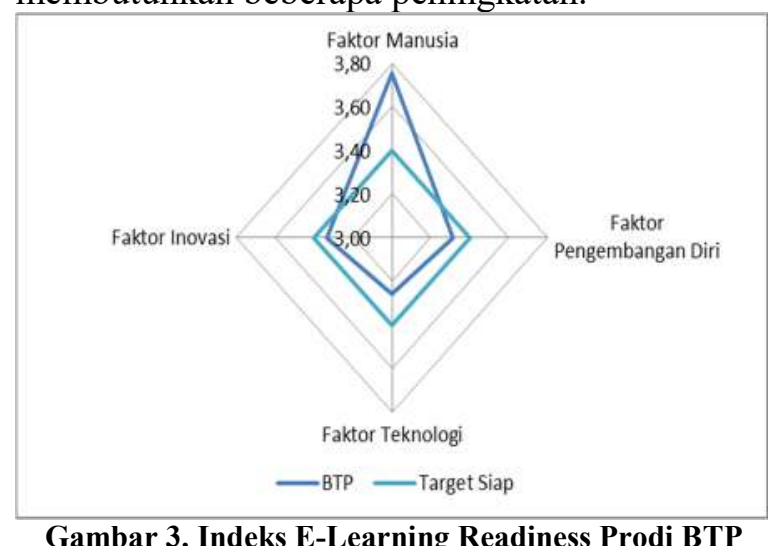

Gambar 3 menujukkan indeks e-learning readiness pada Program Studi BTP, hasil penelitian menggambarkan bahwa program studi ini unggul pada faktor manusia tetapi perlu peningkatan pada faktor pengembangan diri, teknologi dan inovasi.

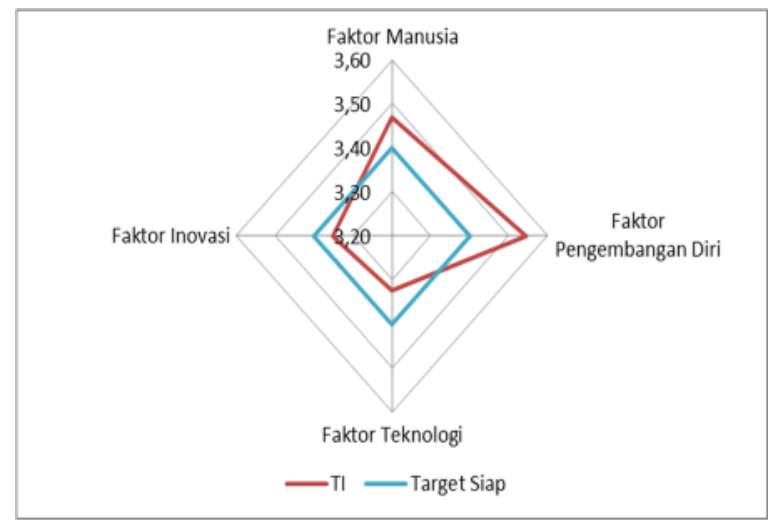

Gambar 4. Indeks E-Learning Readiness Prodi TI

Gambar 4 menunjukkan indeks kesiapan penerapan e-learning pada Program Studi TI, hasil penelitian menyatakan bahwa program studi ini unggul pada faktor manusia dan pengembangan diri, sedangkan faktor teknologi dan inovasi perlu dilakukan peningkatan.

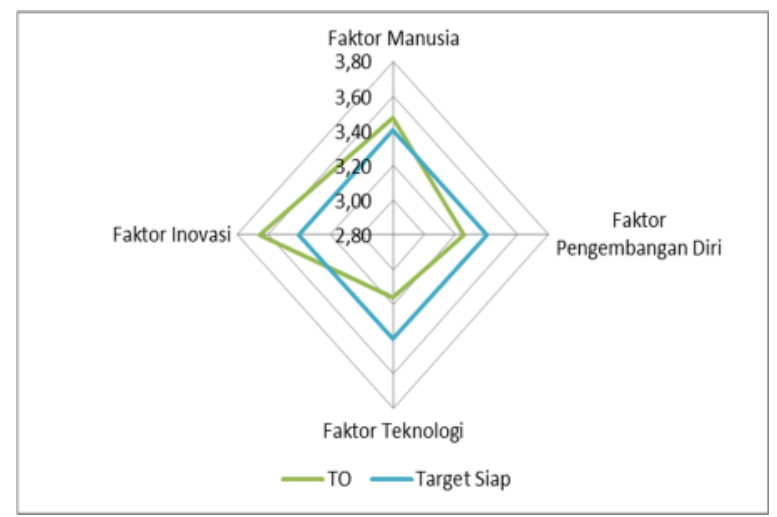

Gambar 5. Indeks E-Learning Prodi TO 
Gambar 5 menunjukkan tingkat kesiapan penerapan e-Learning pada program studi TO, hasil penelitian menyatakan bahwa program studi siap dari sisi manusia dan inovasi sedangkan faktor sisi pengembangan diri dan teknologi perlu peningkatan lebih lanjut.

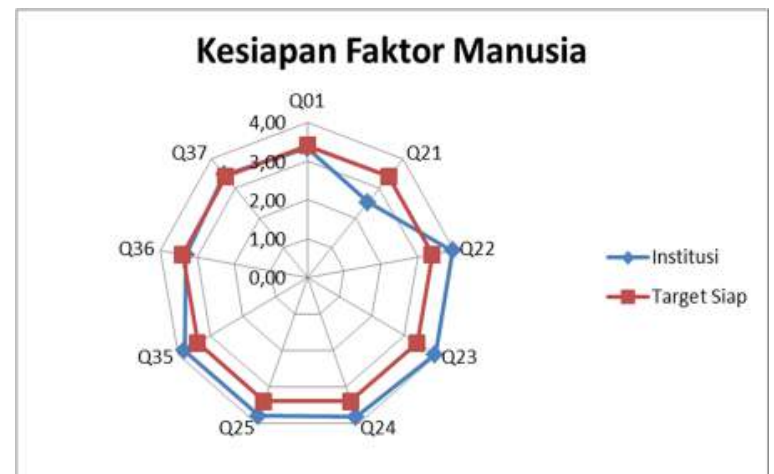

Gambar 6. Indeks ELR berdasarkan Item Pertanyaan Faktor Manusia

Gambar 6 menunjukkan indeks ELR pada level institusi berdasarkan item pertanyaan pada faktor manusia, ada beberapa hal yang harus dibenahi antara lain : (1) Perlu peningkatan pada pelaksanaan penerimaan mahasiswa baru terutama pada sisi promosi sehingga dapat melakukan seleksi siswa yang berprestasi dan memiliki nilai akademik yang baik (Q01), (2) Perlu dilakukan pelatihan pengorganisasian dan evaluasi pembelajaran berbasis e-learning untuk dosen sehingga dapat menciptakan kerjasama yang baik antara dosen dan mahasiswa dalam pembelajaran (Q21 dan Q36).

Gambar 7 menunjukkan indeks ELR pada level institusi berdasarkan item pertanyaan pada faktor pengembangan diri, hal yang harus dibenahi adalah pengelolaan sumber dana untuk anggaran terkait dengan keberlangsungan penerapan e-Learning. Perlu disediakan waktu khusus untuk pembahasan anggaran e-Learning (Q18 dan Q19).

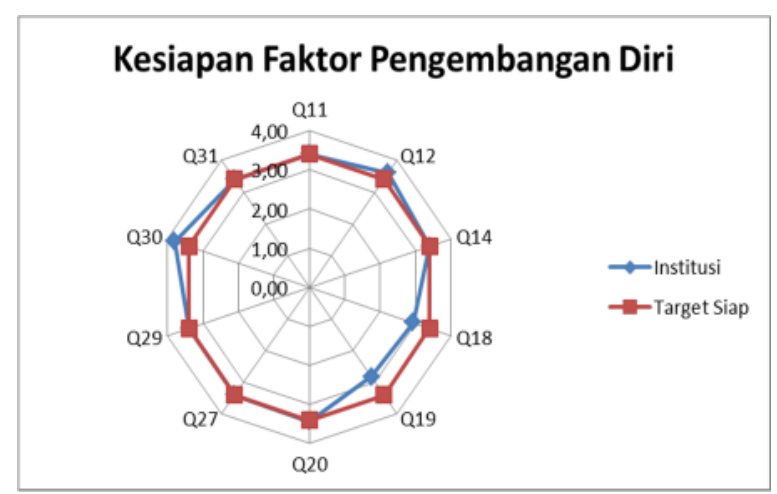

Gambar 7. Indeks ELR berdasarkan Item Pertanyaan Faktor Pengembangan Diri

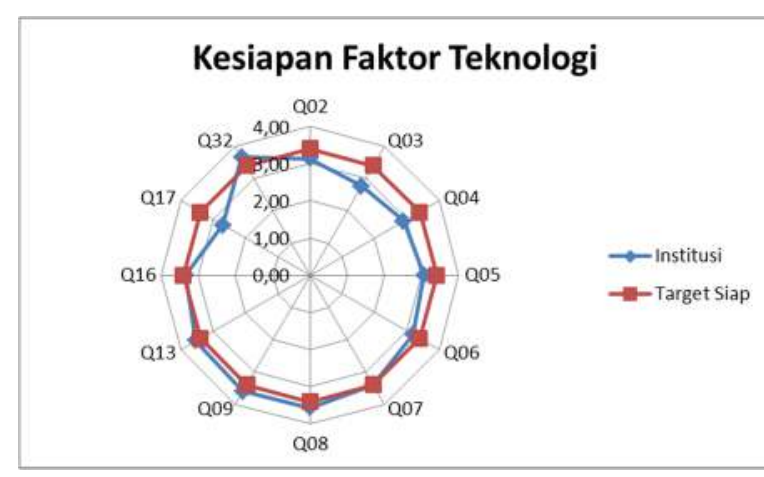

Gambar 8. Indeks ELR berdasarkan Item Pertanyaan Faktor Teknologi

Gambar 8 menunjukkan indeks ELR pada level institusi berdasarkan item pertanyaan pada faktor teknologi, ada beberapa hal yang harus dibenahi antara lain : (1) Sarana dan prasarana Laboratorium Komputer harus ditingkatkan sehingga mahasiswa dapat mengakses komputer secara individual (Q02), (2) Perlu peningkatan pada fasilitas akses intenet (Q03), (3) Peningkatan pada kehandalan perangkat lunak sehingga tidak terjadi kendala pada saat akses di luar kampus (Q04), (4) Perlu adanya penyesuaian pada kurikulum terutama pada program studi BTP dan TO terkait dengan kemampuan komputer dasar mahasiswa (Q05 dan Q06).

Gambar 9 menunjukkan indeks ELR pada level institusi berdasarkan item pertanyaan pada faktor inovasi, hal yang harus dibenahi adalah pelatihan untuk tenaga kependidikan terkait dengan pengelolaan fasilitas e-Learning (Q34).

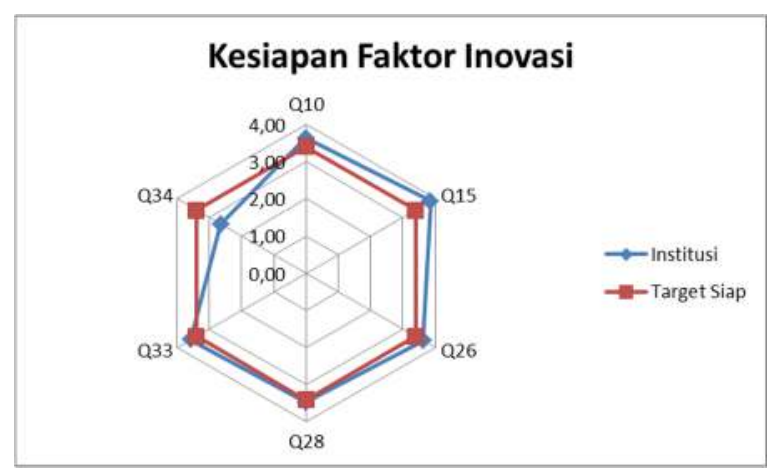

Gambar 9. Indeks ELR berdasarkan Item Pertanyaan Faktor Inovasi

\section{PENUTUP}

\section{Kesimpulan}

Berdasarkan hasil penelitian dapat disimpulkan antara lain : (1) Secara umum Politeknik Hasnur mempunyai indeks 3,41 yang 
termasuk dalam kategori siap dalam penerapan $e$ Learning tetapi perlu beberapa peningkatan terutama pada faktor pengembangan diri dan teknologi. (2) Pada level program studi, Program Studi BTP dan TI termasuk dalam kategori siap dalam penerapan e-Learning tetapi perlu peningkatan terutama pada faktor pengembangan diri, teknologi dan inovasi, (3) Pada level institusi perlu dilakukan peningkatan pada pelaksanaan penerimaan mahasiswa baru, perlu adanya pelatihan pengorganisasian dan evaluasi pembelajaran berbasis e-Learning, pengelolaan sumber dana untuk anggaran, peningkatan sarana dan prasarana laboratorium, peningkatan fasilitas internet, penyesuaian kurikulum dan pelatihan untuk tenaga kependidikan dalam pengelolaan elearning.

\section{Saran}

Berdasarkan temuan penelitian yang telah dibahas sebelumnya, Politeknik Hasnur diharapkan dapat melakukan peningkatan sesuai dengan rekomendasi yang diusulkan. Politeknik Hasnur harus secara berkala melakukan pengukuran tingkat kesiapan penerapan $e$ Learning sebagai bahan evaluasi untuk peningkatan yang berkelanjutan. Untuk penelitian selanjutnya, perlu dikembangkan ruang lingkup yang lebih termasuk menggunakan mahasiswa sebagai responden dalam penelitian berikutnya.

\section{REFERENSI}

Al-Busaidi, K., \& Al-Shihi, H. (2012). Key factors to instructors' satisfaction of learning management systems in blended learning. Journal of Computing in Higher Education, 18-39.

Angraini, \& Suryadi, D. (2015). Pengukuran Tingkat Kesiapan Penerapan E-Learning Menggunakan TRI (Technology Readiness Index), Studi Kasus: UIN Suska Riau. Jurnal SISFO : Inspirasi Profesional Sistem Informasi.

Astuti, N., \& Nasution, R. (2014). Technology Readiness and E-Commerce Adoption among Entrepreneurs of SMEs in Bandung City, Indonesia. Gadjah Mada International Journal of Business.
Aydin, G., \& Tasci. (2005). Measuring Readinesss for e-Learning: Reflection from Emerging Country. Educational Technology and Society Journal.

Blin, F., \& Monro, M. (2008). Why hasn't technology disrupted academics' teaching practices? Understanding resistance to change through the lens of activity theory. Computers \& Education, 475-490.

Chapnick, S. (2000). Are You Ready for ELearning? Learning Circuits: ASTD's Online Magazine All About E-Learning.

Clark, R., \& Mayer, R. (2011). E-Learning and the science of instruction: Proven guidelines for consumers and designers of multimedia learning. John Wiley \& Son.

Fariani, R. (2013). Pengukuran Tingkat Kesiapan E-Learning (E-Learning Readiness) Studi Kasus pada Perguruan Tinggi ABC di Jakarta. Paper presented at the Seminar Nasional Aplikasi Teknologi Informasi (SNATI).

Gillard, S., Bailey, D., \& Nolan, E. (2008). Ten reasons for IT educators to be early adopters of IT innovations. Journal of Information Technology Education, 2133.

Gotthardt, M., Siegert, M., Schlieck, A., Schneider, S., Kohnert, A., \& Gross, M. (2006). How to successfully implement E-Learning for both students and teachers. Academic Radiology.

Naveh, G., Tubin, D., \& Pliskin, N. (2012). Student satisfaction with learning management systems: A lens of critical success factors. Technology, Pedagogy and Education, 337-350.

Oketch, H., Njihia, J., \& Wausi, A. (2014). ELearning Readiness Assessment Model In Kenyas' Higher Education Institutions: A Case Study Of University Of Nairobi. International Journal of Scientific Knowledge. 
Ong, C.-S., Lai, J., \& Wang, Y. (2004). Factors affecting engineers' acceptance of asynchronous e-Learning systems in high-tech companies. Information \& management, 795-804.

Pamukti, U., Hartanto, R., \& Winarno, W. (2017). Model Analisis Kesiapan Individu dalam Penerapan Manajemen Pengetahuan di Instansi Pemerintah. CITEE.

Parasuraman, A. (2000). Technology Readiness Index (TRI) a Multiple-Item Scale to Measure Readiness to Embrace New Technologies. Journal of Service Research, 307-320.

Peffers, K., Tuunanen, T., Rothenberger, M., \& Chatterjee, S. (2007). A Design Science Research Methodology for Information Systems Research. Journal of Management Information Systems, 4578.

Standish. (2014). Chaos Report. London.

Steel, C. (2009). Reconciling university teacher beliefs to create learning designs for LMS environments. Australasian Journal of Educational Technology, 399-420.

Stockley, D. (2003). E-Learning Definition and Explanation. Diambil kembali dari http://derekstockley.com.au/e-Learningdefinition.html

Wannemacher, K. (2006). Functional Differentiation of Incentives for Eteaching at Universities. Current Developments in Technology-Assisted Education, 72-76.

Watts, N. (2007). Bringing online learning to a research-intensive university. Diambil kembali dari http://elearnmag.acm.org/featured.cfm?a id $=1291534$

Wuryanto, N., \& Insani, N. (2013). Tingkat Kesiapan (Readiness) Implementasi ELearning Disekolah Menengah Atas Kota Yogyakarta. Jurnal Pendidikan Matematika dan Sains. 